\title{
Short communication Metabolic approaches to breast cancer treatment and prevention
} Anthony Howell

CRUK Department of Medical Oncology, University of Manchester, Christie Hospital, Manchester M20 4BX, UK

Corresponding author: Anthony Howell, anthony.howell@christie.nhs.uk

Published: 20 December 2007

This article is online at http://breast-cancer-research.com/content/9/S2/S27 (c) 2007 BioMed Central Ltd

Standard systemic therapy for breast cancer treatment and prevention are generally directed at reduction in cell growth and increase in apoptosis by direct inhibition of DNA synthesis or signalling pathways that control cell proliferation and cell death. Data are accumulating that calorie restriction (CR) and/or exercise, or agents that target metabolic pathways may have antitumour effects either alone or in combination with standard therapies for cancer prevention and treatment, and merit further investigation. Here, we outline evidence concerning the effectiveness of this approach.

The first observation, that energy restriction could retard tumour growth, was reported nearly 100 years ago [1]. More recently, Dirx and colleagues [2] conducted a meta-analysis of 14 studies of the effect of calorie restriction on spontaneous mammary tumour development in mice and found that the pooled risk difference between mice given restricted access and those given free access to food was 0.55 (95\% confidence interval 0.41-0.69), irrespective of the type of restricted nutrient. Whether CR affects human tumour development is not clear. Epidemiological studies indicate lower risk for breast cancer in women who have a period of weight loss as compared with those who maintain or continued to gain weight in mid-life $[3,4]$. Excess weight at diagnosis and weight gain during breast cancer treatment increases mortality from cancer and co-morbid conditions, whereas diet modification reduces recurrence $[5,6]$.

Although the data outlined above suggest that CR is effective at preventing breast cancer and possibly inhibiting the growth of overt tumours, currently it is unrealistic to expect CR to be implemented on a population basis. This has led to studies on whether intermittent CR is potentially more acceptable [7] and investigation of pharmacological agents that might mimic the effect of CR (calorie restriction mimetics [CRMs]) [8]. In order to establish targets for CRM, it is important to gain an understanding of the cellular and biochemical basis of CR.

Several animal studies have shown that CR inhibits cell proliferation and stimulates apoptosis (for review, see [8]). The experimental data are consistent with cell cycle arrest at the
Breast Cancer Research 2007, 9(Suppl 2):S27 (doi:10.1186/bcr1825)

$\mathrm{G}_{1} / \mathrm{S}$ transition and a shift into $\mathrm{G}_{0}$ with appropriate reductions in cyclin kinases and increases in p21 and p27. Caspase activity assays showed that caspase 9 and 3 are elevated in the mammary tumours of CR rats, as compared with carcinomas from fed animals given free access to food, which implies the mitochondrial pathway of apoptosis is activated by CR [9].

Mechanistic studies on cell proliferation reduction and apoptosis activation are highly important but they do not indicate how a reduction in calories is translated into these effects on mammary tumour cells. Reduction in the major components of the diet (carbohydrate, lipids and proteins) must affect tumour cell metabolism in some way, with secondary results in alterations in cell cycle and cell death pathways. It is of interest that Dirx and coworkers [2] reported in their overview that $C R$ was effective whatever the component of diet was restricted. Thus, there may be more than one metabolic pathway that mediates $\mathrm{CR}$.

In general, breast tumour metabolic pathways appear to be different compared with the normal cells from which they arise. Warburg [10], in the 1920s, was the first to show that glycolysis was markedly increased, and later Weinhouse and colleagues [11] demonstrated that fatty acid synthesis was also markedly increased in tumours. Warburg suggested that high glycolytic rates in tumours were related to defects in tumour mitochondria, and considerable support for this hypothesis has recently accumulated [12].

An important advance in our understanding of how cells sense their own energy status was the discovery of adenosine monophosphate-related kinase (AMPK), which is activated when cellular energy levels are reduced (low AMP/ATP ratio) [13]. Activation of AMPK results in reduction in cell synthetic (anabolic) pathways and increase in catabolic pathways and oxidative phosphorylation (to generate ATP), with associated reduction in cell proliferation. Some metabolic pathways in tumours are shown in Figure 1. Increased glycolysis and lipid synthesis may be thought of as oncogenic and enzymes in the AMPK/tricarboxylic acid (TCA) cycle pathway as tumour suppressors. Indeed, transfection of 
Figure 1

\section{Energy pathways in tumours}

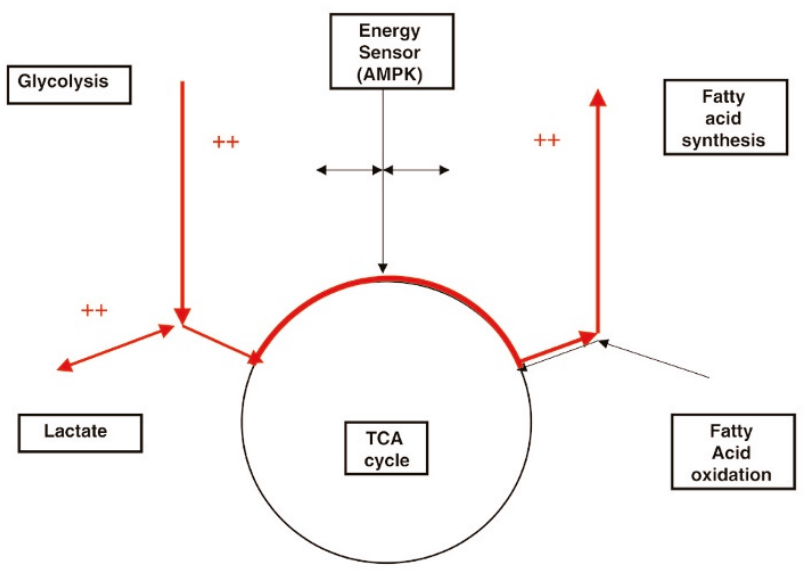

Simplified view of metabolic pathways in tumours. Enhanced pathways are shown as thick lines. Potential inhibitors of glycolysis and lipid synthesis and stimulators of the tricarboxylic acid (TCA) cycle are shown. Calorie restriction would be expected to enhance adenosine monophosphate-related kinase (AMPK) activity, which inhibits lipid synthesis and generally stimulates TCA cycle activity.

glycolytic enzymes into normal cells results in immortalization [14], and mutations in components of the LKB1/AMPK pathway result in tumour formation consistent with their tumour suppression function (Figure 1).

The mechanism of action of some known CRMs is consistent with the 'oncogene'/tumour suppressor gene concept outlined above. For example, inhibition of glycolysis in MCF7 cells with 2-deoxyglucose [15] or of fatty acid synthesis [16] with the fatty acid and synthase inhibitor C93, or stimulation of AMPK synthesis with the antidiabetic drug metformin [17] all inhibit proliferation of human MCF7 cells in vitro. Also, enhancement of TCA cycle activity is associated with inhibition of cell growth. In tumours entry of pyruvate into the TCA cycle may be reduced either by metabolism to lactate or inhibition of pyruvate dehydrogenase by pyruvate dehydrogenase kinase (PDK). Inhibition of lactate dehydrogenase activity by small interfering RNA [18] or of PDK by 2-chloroacetate stimulates mitochondrial activity [19] and is associated with inhibition of tumour cell growth or direct stimulation of TCA cycle activity using cell-permeating $\alpha$-ketoglutarate [20].

The examples given above indicate that alteration in tumour cell metabolism is a potential approach, either alone or in addition to standard therapies for the prevention and treatment of breast cancer.

\section{Acknowledgement}

This article has been published as part of Breast Cancer Research Volume 9 Supplement 2, 2007: Controversies in Breast Cancer. The full contents of the supplement are available online at http://breastcancer-research.com/supplements/9/S2.

\section{References}

1. Moreschi C: Beziehungen zwischen ernährung und tumorwachstum. Z Immunitätsforsch Orig 1909, 2:651-675.

2. Dirx MJ, Zeegers MP, Dagnelie PC, van den Bogaard T, van den Brandt PA: Energy restriction and the risk of spontenous mammary tumors in mice: a meta-analysis. Int J Cancer 2003 , 106:766-770.

3. Harvie M, Howell A, Vierkant RA, Kumar N, Cerhan JR, Kelemen LE, Folsom AR, Sellers TA: Association of gain and loss of weight before and after menopause with risk of postmenopausal breast cancer in the lowa women's health study. Cancer Epidemiol Biomarkers Prev 2005, 14:656-661.

4. Eliassen AH, Colditz GA, Rosner B, Willett WC, Hankinson SE: Adult weight change and risk of postmenopausal breast cancer. JAMA 2006, 296:193-201.

5. Kroenke CH, Fung TT, Hu FB, Holmes MD: Dietary patterns and survival after breast cancer diagnosis. J Clin Oncol 2005, 23: 9295-9303.

6. Chlebowski RT, BlackburnGL, Thomson CA, Nixon DW, Shapiro A, Hoy MK, Goodman MT, Giuliano AE, Karanja N, McAndrew P, et al.: Dietary fat reduction and breast cancer outcome: interim efficacy results from the Women's Intervention Nutrition Study. J Nat/ Cancer Inst 2006, 98:1767-1776.

7. Cleary MP, Jacobson MK, Phillips FC, Getzin SC, Grande JP, Maihle NJ: Weight-cycling decreases incidence and increases latency of mammary tumors to a greater extent than does chronic caloric restriction in mouse mammary tumor virustransforming growth factor-alpha female mice. Cancer Epidemiol Biomarkers Prev 2002, 11:836-843.

8. Lane MA, Roth GS, Ingram DK: Caloric restriction mimetics: a novel approach for biogerontology. Methods Mol Biol 2007, 371:1143-1149.

9. Thompson HJ, Zhu Z, Jiang W: Dietary energy restriction in breast cancer prevention. Mammary Gland Biol Neoplasia 2003, 8:133-142.

10. Warburg O: On the origin of cancer cells. Science 1956, 123: 309-314.

11. Medes G, Thomas A, Weinhouse S: Metabolism of neoplastic tissue. IV. A study of lipid synthesis in neoplastic tissue slices in vitro. Cancer Res 1953, 13:27-29.

12. Modica-Napolitano JS, Kulawiec M, Singh KK: Mitochondria and human cancer. Curr Mol Med 2007, 7:121-131.

13. Hardie DG: AMP-activated/SNF1 protein kinases: conserved guardians of cellular energy. Nat Rev Mol Cell Biol 2007, 8: 774-785.

14. Kondoh H, Lieonart ME, Gil J, Wang J, Degan P, Peters G, Martinez D, Carnero A, Beach D: Glycolytic enzymes can modulate cellular life span. Cancer Res 2005, 65:177-185.

15. Zhu Z, Jiang W, McGinley JN, Thompson HJ: 2-Deoxyglucose as an energy restriction mimetic agent: effects of mammary carcinogenesis and on mammary tumor cell growth in vitro. Cancer Res 2005, 65:7023-7300.

16. Zhou W, Han WF, Landree LE, Thupari JN, Pinn ML, Bililign T, Kim EK, Vadlamudi A, Medghalchi SM, El Meskini R, et al.: Fatty acid synthase inhibition activates AMP-activated protein kinase in SKOV3 human ovarian cancer cells. Cancer Res 2007, 67: 2964-2971.

17. Zakikhani M, Dowling R, Fantus IG, Sonenberg N, Pollak M: Metformin is an AMP kinase-dependent growth inhibitor for breast cancer cells. Cancer Res 2006, 66:10269-10273.

18. Fantin VR, St-Pierre J, Leder P: Attenuation of LDH-A expression uncovers a link between glycolysis, mitochondrial physiology, and tumour maintenance. Cancer Cell 2006, 9:425-434.

19. Bonnet S, Archer SL, Allalunis-Turner J, Haromy A, Beaulieu C, Thompson R, Lee CT, Lopaschuk GD, Puttagunta L, Bonnet S, et al.: A mitochondria- $\mathrm{K}^{+}$channel axis is suppressed in cancer and its normalization promotes apoptosis and inhibits cancer growth. Cancer Cell 2007, 11:37-51.

20. MacKenzie ED, Selak MA, Tennant DA, Payne LJ, Crosby S, Frederiksen CM, Watson DG, Gottlieb E: Cell-permeating alphaketoglutarate derivatives alleviate pseudohypoxia in succinate dehydrogenase-deficient cells. Mol Cell Biol 2007, 27:3282-3289. 